\title{
The use of neurotechnology in marketing
}

\author{
Svetlana V. Karpova ${ }^{1}$, Olga E. Ustinova ${ }^{2}$ \\ ${ }^{1}$ Department of the Logistics and Marketing, ${ }^{2}$ Department of Management \\ Financial University under the Government of the Russian Federation \\ Moscow, Russia \\ 1'SVKarpova@fa.ru, ${ }^{2}$ OEUstinova@fa
}

\begin{abstract}
In the current conditions of digitalization of the economy in marketing research, there is a steady interest in studying technologies aimed at promoting the brand, goods and services that are used by manufacturing companies and advertisers. Given the rapid pace of change affecting almost all areas of consumer activity, there is a need to analyze the use of modern marketing technologies. In this paper, we study the influence of neurolinguistic and neuromarketing technologies on consumer behavior. The results of research work carried out in accordance with the order of the Financial University under the Government of the Russian Federation dated 05.06.2019 No. $1115 / 0$ "Assessment of the impact of neurolinguistic manipulations on consumer behavior in the conditions of digital transformation of society" are presented.
\end{abstract}

Keywords: marketing technology; advertising; neurolinguistic programming; neuromarketing

\section{INTRODUCTION}

The penetration of digital technologies in the daily lives of consumers determines their use by marketers in order to influence the behavior of potential buyers. The following research results indicate the active use of neurolinguistic and neuromarketing technologies in advertising. Advertisers quite often create advertising messages by manipulating the language, claiming that the message contains true information. Through this method, consumers are attracted to a product or service, even if they are not true. To make a profit, companies quite often resort to slogans and sounds. At the same time, the language used in various types of advertising information has a huge impact on the potential buyer.

The main issue is the identification of the degree of influence of used neurotechnologies on consumer behavior. This study was conducted as part of an applied research project on state assignments for 2019 (the theme "Assessing the Impact of Neurolinguistic Manipulations on Consumer Behavior in a

Digital Transformation of Society" approved by the Deputy Prime Minister of the Russian Federation dated March 28, 2019).

\section{LITERATURE REVIEW}

The comprehension of the experience of neurolinguistic programming (NLP) and its registration in the model and technique made it possible to quickly go beyond the boundaries of psychotherapy. Today, the principles and techniques of NLP are in demand in various fields when addressing issues related to improving the competence of employees, managing time planning, creativity, innovation, etc. Neuro-linguistic programming was developed and proposed by American scientists John Grinder and Richard Bandler in the 80s of the last century. In the practical aspect, neurolinguistic programming can be defined as the study of outstanding results in the activities of individuals in various fields in the process of communication, as the art and science of personal mastery [1], [2], [3], [4]. In the conditions of increasing competition when creating advertising messages, marketers are actively using the practice of neurolinguistic programming.

The development of consumer culture and the study of the behavioral aspects of the buyer led to the emergence of a new direction in marketing - neuromarketing. The consumer in relation to their purchasing behavior and assessment of the quality of goods and services is becoming increasingly unpredictable. Previously, the focus was on consumer properties and service. However, 
the requirements of the modern buyer are growing rapidly, in this regard, sales are reaching a new emotional level. The applied marketing methods and tools lose their effectiveness and relevance. Thus, the development of a new area of neuromarketing has agreat potential in the successful implementation of the company's strategy. The concept of neuromarketing is to study the human subconscious with the help of appropriately selected images. Among scientists involved in this issue, scientists from various scientific fields should be distinguished, among them A. Traindl [7], D. Lewis [5], well-known experts in marketing, advertising and related business areas M. Lindstrom [6], D. Praet et al. With the help of neuromarketing, without using traditional marketing methods and tools, it becomes possible to obtain qualitatively new and reliable information about the personal preferences of consumers. They are designed to demonstrate the involuntary reaction of the body of potential buyers to any stimulus (color, sound, shape, behavior, etc.). The indicators are any manifestations of the body, including pupil movement, palpitations, sweating, pressure and others.

Creating advertising messages, marketers try to use mechanisms that remove internal barrier filters, while manipulating consumer behavior.

\section{METHODS}

When carrying out the study, general scientific methods of cognition were used, based on system-logical and interdisciplinary approaches. For processing and summarizing information, grouping methods, empirical, statistical, graphical and other methods were used.

As part of the research, a survey of residents of Moscow was conducted. The calculation of the volume of the sample for the survey with a known volume of the population is made according to the following formula 1 :

$$
n=\left(t^{2 *} \sigma^{2 * N}\right) /\left(N^{*} \Delta^{2}+t^{2 *} \sigma^{2}\right)
$$

where $n$ is the sample size, $\Delta$ is the magnitude of the permissible error in fractions, $N$ is the size of the general population, $t$ is the confidence coefficient (confidence criterion), $\sigma$ is the dispersion or dispersion measure of the feature under study, which characterizes the deviation from the average values in the general population

The determination of the required number of sampling units is based on the following parameters: the marginal sampling error is 0.05 , and the confidence coefficient is 2 with a variance of 0.5 . These parameters provide high reliability of the survey results in $95 \%$ of cases with marginal error of $\pm 5 \%$. According to the Federal State Statistics Service [8], the population of Moscow as of 01.01.2018. amounted to 12506500 people. However, the study does not include a survey of residents who have not reached working age, therefore, when calculating the sample population, it is advisable to use the Rosstat data without taking into account this age category (12506500-1878900 $=10627600$ people). Thus, the determination of the required sample size in accordance with the specified formula with a target audience of 10627600 people is:

\section{$n=\left(2^{2 *} 0.25 * 10627600\right) /\left(\mathbf{1 0 6 2 7 6 0 0} * 0.05^{2}+2^{2 *} 0.25\right)=\mathbf{4 0 0}$ the respondents}

Such a sample size is sufficient to obtain representative sociological data as a result of the survey.

\section{DISCUSSION AND RESULTS}

It is known that people consider themselves immune to the advertising that surrounds them. Nevertheless, language manipulation is a fairly effective and successful strategy in achieving the goals of companies. The illusion of consumer immunity to advertising makes them even more vulnerable to the various methods advertisers use. They fill advertisements with information, using certain manipulative techniques to attract the target audience to their products. At the same time, consumers think that they are buying an excellent product, although in reality this is not so.

Advertisers are aware of the public's susceptibility to advertising and take advantage of it. The results of the survey (Figure 1) confirm this thesis: $43.0 \%$ of respondents believe that they will not allow themselves to be deceived and gain something by seeing the advertised object, among which there are more women. Under the influence of advertising, $37.2 \%$ of respondents sometimes make a purchase and only $18.2 \%$ realize that an advertising message encourages them to 
purchase a product or service. Consumers from different age groups, different income levels and social status confirm the general distribution of votes.

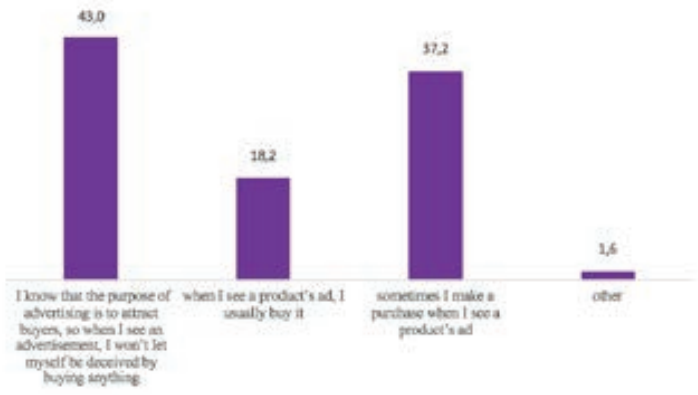

Fig. 1. Self-assessment of the impact of advertising (\%) Source: compiled by the authors

Some words reinforce the statements that follow them. But in reality they only distract attention, making them less significant or even completely useless. One of them is the word "do." So, for example, on the statement "Save up to $40 \%$ ", consumers often skip the word "up" and believe that they will save $40 \%$. In addition, the "do" has a sense of upward movement, which in us translates as a general good feeling. Everything that is between zero and the number after "before" is included in this statement, so the phrase "save up to $40 \%$ " literally means "save from $0 \%$ to $40 \%$ ". The survey proves this assumption. So, answering the question "What percentage do you expect to receive when you see an advertisement..." the majority of respondents $(23.5 \%)$ responded to the maximum amount of savings, moreover, in equal proportions between men and women; $23.0 \%$ of potential buyers turned out to be in the range of expectations of half of the amount of savings indicated by the advertiser. At the same time, $17.5 \%$ of respondents expect to receive savings in the maximum range. Slight fluctuations in anticipation of savings were shown by age groups, regardless of education, social status and income level (Fig. 2).

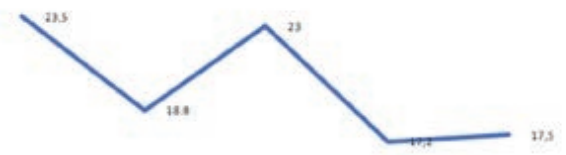

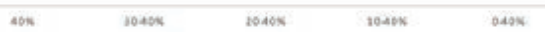

Fig. 2. Expectations of customers with the wording "... You will save up to $40 \%$ " (\%) Source: compiled by the authors 
An approval is a verbal or printed part of an advertisement that contains the superiority of the advertised product. While some of them are honest statements about products, others, on the contrary, are false information. However, most of the statements are in the middle: "neither a bold lie, nor useful information for consumers." These statements are most dependent on the manipulation of the language in order to attract consumers to their products.

Quite often you can find advertisement campaigns that include giving gifts to potential buyers. The survey showed that $38.5 \%$ of respondents are likely to accept them, while realizing that they will be offered to purchase it in the future, and this indicator is higher for people 55 years old and older and, conversely, lower for people with higher education or a scientist power. $24.5 \%$ of respondents are wary of this kind of advertising campaigns (Figure 3). A common way to get acquainted with the brand is considered by $19.3 \%$ of respondents. Thus, advertisers achieve their goals and attract the attention of potential buyers to their brand, because only $6.3 \%$ of respondents refuse to accept a gift. Slight fluctuations in the total data are observed in people with different social status and income levels.

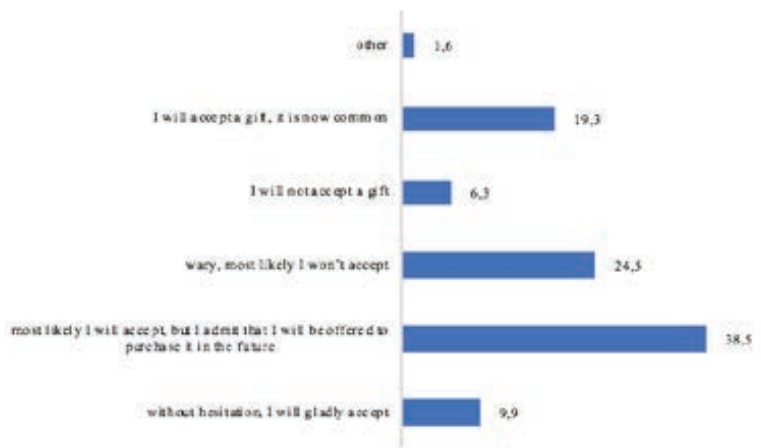

Fig. 3. Attitude to the offer in advertising to receive a product as a gift (\%) Source: compiled by the authors

Correlation of answers to the question regarding the characteristics of the perception of online advertising by consumers of different socio-demographic groups, revealed a number of characteristic features. Thus, advertising that is relevant to the respondent's existing needs and evokes positive emotions is most important for buyers with a higher education (including a scientific degree), middle-aged employees, and high-income employees. However, advertising related to the respondent's field of activity is more interesting to older men with high income and a high level of education. The nonstandard plot in advertising often attracts the attention of highincome consumers employed as a manager or employee.

Given the increasing penetration of digital technology into the life of every person, social networks are another powerful digital channel for influencing consumer behavior. Their capabilities help companies in the course of market activities to convey additional information about products/services to consumers, to inform them about current promotions and special offers, to help solve problems. An analysis of the data showed that the vast majority of survey participants $(81.3 \%)$ have personal pages on social networks. Moreover, more than half of the respondents (53.6\% in total) are active users (39.0\% "several times a day" and $14.6 \%$ "once a day" view pages on social networks). Another fourth of the respondents are interested in actions on their personal pages once or several times a week (Figure 4). 


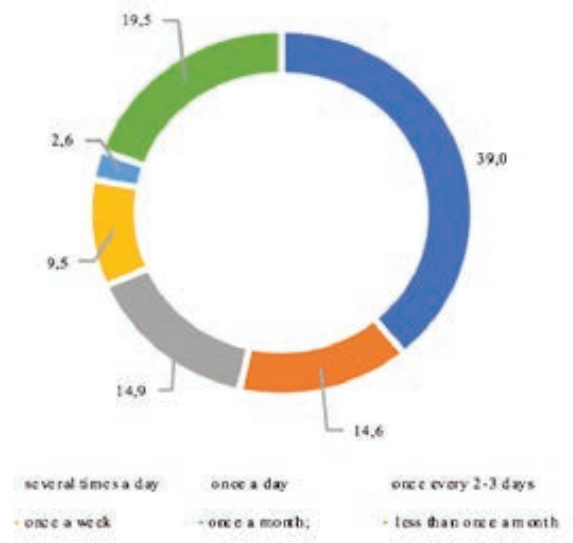

Fig. 4. Frequency of browsing personal pages in social networks (\%)

Source: compiled by the authors

Moreover, half of the respondents (55.6\%) never in the process of their choice of goods/services visit the official accounts of seller companies and only $6.4 \%$ always do this. As a rule, consumers who are interested in social media sales company pages are young women with higher education who are engaged in high-income intellectual work.

The results of the study indicate that neuro-linguistic and neuromarketing technologies have penetrated the sphere of consumption and have a manipulative effect on consumer behavior.

\section{CONCLUTION}

As part of the applied research work on the state assignment for 2019, using traditional marketing methods (questionnaires), an analysis of the use of neurolinguistic programming techniques that affect the perception of advertising information by consumers was carried out (topic "Assessing the impact of neurolinguistic manipulations on consumer behavior in the context of digital transformation of society" approved by the Deputy Prime Minister of the Russian Federation dated March 28, 2019 No. 2768p-P17). The results of the study prove that the need to study neurolinguistic and neuromarketing technologies in modern conditions is becoming especially urgent. However, given the ambiguity of positions regarding the possibilities of using this method of sales promotion, we will dwell on some problems of its development:

- norms in the field of neuromarketing are not clearly defined; in this regard, it is necessary to create a set of scientific, legal and ethical standards that regulate and ensure the psychological safety of consumers;

- there is a risk of manipulation of consumer behavior and the elimination of personal responsibility for making decisions in the process of making a purchase;

- special protective measures should be developed for vulnerable populations.

Given the above, it can be stated that at present there are practically no generally accepted ethical and legal norms governing relations in the field of the use of neuromarketing technologies. However, it should be noted that in different countries they solve these issues differently.

In modern conditions of consumption, neuromarketing is becoming one of the most powerful tools for manipulating consumers. Neuroimaging methods provide specialists and experts not only the ability to predict consumer behavior, but also manage it. Neuromarketing allows you to choose the most effective ways of convincing consumers, creating a trusting relationship with advertised objects. 


\section{REFERENCES}

[1]. Bandler R., Grinder J., Andreas S. Frogs into Princes: Neuro Linguistic Programming. Moab, Utah: RealPeoplePress, 1979.

[2]. Derks L., Hollander J. The Essence of NLP. The Keys to Personal Development. Moscow: $\mathrm{KSP}+, 2000$.

[3]. Dilts R.B. Strategies of Genius, vol. I. Scotts Valley: Dilts Strategy Group, 2017.

[4]. Johnson R. 40 NLP Training Exercise: Pract. Psychology course: human relationships and their influence on each other/Transl. from English A. Akopyan. Moscow: KSP +, 2001.

[5]. Lewis D. The Brain Sell: When Science Meets Shopping; How the new mind sciences and the persuasion industry are reading our thoughts, influencing our emotions, and stimulating us to shop. London: Nicholas Brealey Publishing. 2013.

[6]. Lindstrom M. Buyology: How Everything We Believe About Why We Buy is Wrong. London, 2010.

[7]. Traindl A. Neuromarketing. Visualization of Emotions. Moscow: Alpina Business Books, 2019.

[8]. Federal State Statistic Service. Available at: http://moscow.gks.ru/wps/wcm/connect/rosstat ts/moscow/ru/statistics/p opulation/. 